\title{
Pocket Braille Keyboard - Reader using Braille Back Service
}

\author{
Mohammed Abdul Razzak ${ }^{\mathrm{a}}$, James A.Lordson Benhurr ${ }^{\mathrm{a}}$, Chintan Tawadia ${ }^{\mathrm{a}}$, Mohammad \\ Mohatram $^{\mathrm{a}}$, Neha Joseph ${ }^{\mathrm{a}}$
}

Major disadvantage of Existing Braille Keyboard is the Cost which is greater than $3500 \$$ and size more than $15 \mathrm{~cm}$. Out of 285 million visually impaired people, not many are able to afford it and it's hefty to carry around. This project presents the making of Pocket Braille Keyboard-Reader of less cost, around 100\$, and more compact in size. Principle technologies used are capacitive touch sensing and MEMs (Micro-Electrical Mechanical systems) for typing and reading respectively, which will be assisting the visually impaired people to interact with the world.

Ex: Reading and typing in Braille Language, interacting with SMART phone with NAVIGATION keys on the Keyboard.

Keywords: Braille Keyboard; Visually impaired; Capacitive sensing; MEMS Technology; Braille Cell; Arduino Micro; Perkins Braille Format; Braille Alphabet.

\section{Introduction}

From Legos that can convert text to braille to ultrasounds that help blind mothers see their babies with the help of 3D printing technology to the development of smart canes with ultrasound waves that guide people. In the Past years, the technology for blind / visually impaired People have evolved in a rapid pace.

The Braille language is the universally accepted form of written communication for the visually impaired. A system of rules of dots, arranged in a three row by two editorial grid, is used to exhibit different letters, routine and symbols.

Although the Braille system provides 1000000 of visually impaired mortal with a culture medium for interpretation and piece of writing, a device that allows various information to be read in Braille on a small scale basis has not yet been developed.

Modern technology has made many subsidiary implements for people who read and indite braille. There are some contrivances that engender books in braille and others that let people read information on computers and from the Internet. Some contrivances are simple and inexpensive and others are very intricate. The contrivances utilized by many people sanction them to read braille to consummate their schoolwork, take care of personal business, and do their jobs at work

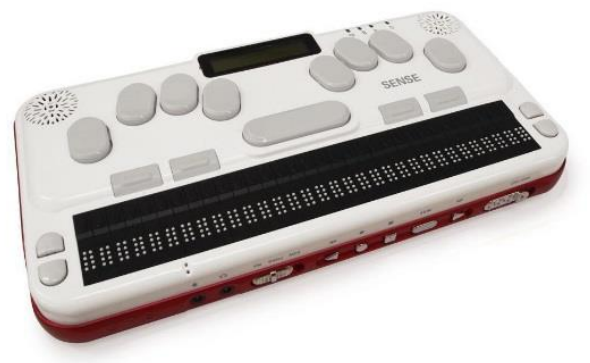

Figure 1. Braille Note taker [1]

Currently, Electronic braille Note takers/Keyboard/braille inditer are portable contrivances with braille keyboards that braille readers can utilize to enter information. The text stored in these contrivances can be read with a built-in braille exhibit or the contrivance can read aloud with a synthesized voice. These contrivances are handy for taking notes in class, and often have built-in address books, calculators, and calendars, additionally. The mechanical braillewriter works scarcely like a typewriter. It has six keys - one for each dot in a braille cella space bar, a backspace key, a carriage return, and a line victual key. However, verbalizing Keyboards can be disruptive in quiet settings and draw attention to the utilizer.

\section{Background}

The idea, the thought behind the project came to us when, the first few of our topics were not accepted for the final year project. During one of our group discussion sessions, we shared various ideas but none of them could catch our attention, then we came across the term "blind" and we decided we have to do our project such that we are able to help the visually impaired people. Now for making any working project to help a visually impaired person, first thing that we need is to have a clear understanding about the problems faced by the visually impaired people.

To clear our doubts, we went to a blind association (Al Noor Blind association, Al-Khuwair, Muscat, Oman), where we met some visually impaired people. Also, we met one of the committee members, who explained us the Braille alphabet system and the typing of Braille alphabets (using a Perkins Braille typewriter), he also told us about how costly some of the equipment's that they use at the association are.

Seeing their equipment's we got the idea to develop a more compact and personalized gadget, to which they can gain access easily and is also easier to carry around for them, and the most important factor we kept in mind while planning our project was the cost.

\section{Objectives}

Currently, people with a visual impairment must rely on Braille Keyboards in order to type or read the information from 
it. However, these keyboards are hefty and are difficult to carry around, also its working is complex. Our goal is to design a braille keyboard-reader that is capable of allowing the visual impaired user to perform their daily jobs.

We will be designing the braille note takers and readers in a more simple and efficient format.

Key problems faced with the functionality of braille technologies includes the braille displays being temperamental with certain programs and older devices being unable to keep pace with the advancement of technology they are based on.

\section{Methodology}

\section{For Typing: (Capacitive sensing technology)}

Consider a retractable banner Pen, as seen in Figure 3, a pen from which paper can be rolled in and out. Now making Circuits on the paper by using Circuit Scribe Pen (a pen that makes circuits), seen in Figure 2, such that it is foldable. Now connecting the circuits to a mini Arduino (microcontroller), whenever the finger is placed on the circuit then the output we get is a letter on the PC or smart phone. This is possible with the help of the capacitive touch sensing technology.

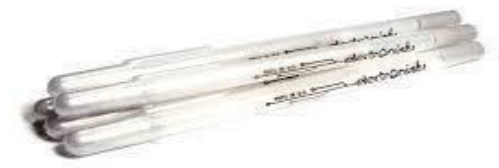

Figure 2. Circuit scribe pen [2]

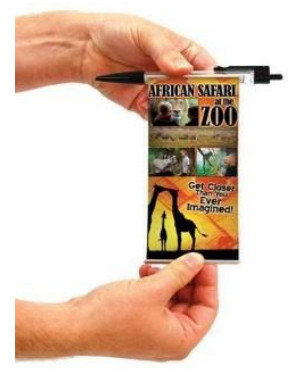

Figure 3. Retractable banner pen [3]

This Technology is associated with the micro controller Arduino which comes with different processors and size (Figure 4). The Arduino used in this project will be the Arduino micro, as this Arduino is of small size it would be easy to accommodate the Arduino with in the body of the pocket braille. (Figure 5)

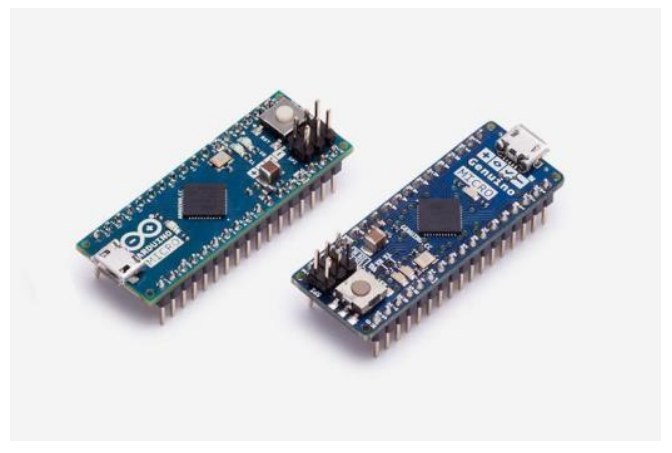

Figure 4. Arduino Micro [4]

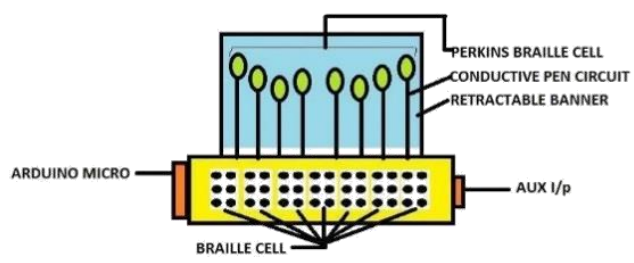

Figure 5. Pocket Braille Layout

The Arduino uses library that converts the pins of the Arduino into a capacitive sensor which can sense the electrical capacitance of the human body. All the sensor setup requires is a medium to high value resistor and a piece of wire and a minuscule (to immensely colossal) piece of Aluminum foil on the cessation. At its most sensitive, the sensor will commence to sense a hand or body inches away from the finger. The Keys present would be made of aluminum foil so that perfect conducting can happen between the fingers and the wire that is attached to the key. [5]

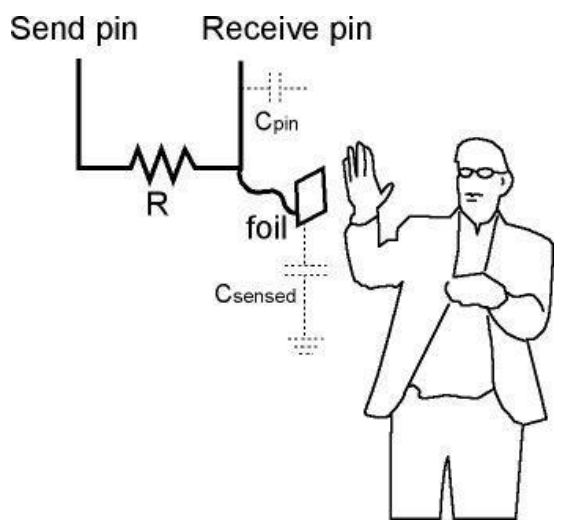

Figure 6. Capacitive touch sensing [6]

Example of the use of capacitive touch sensing can be seen (Figure 7) where the technology is used make a piano. The touch of the piano would make the buzzer ring and produce a sound. Similarly, in this project the touch of the key would give the relative character with respective to the braille format. 


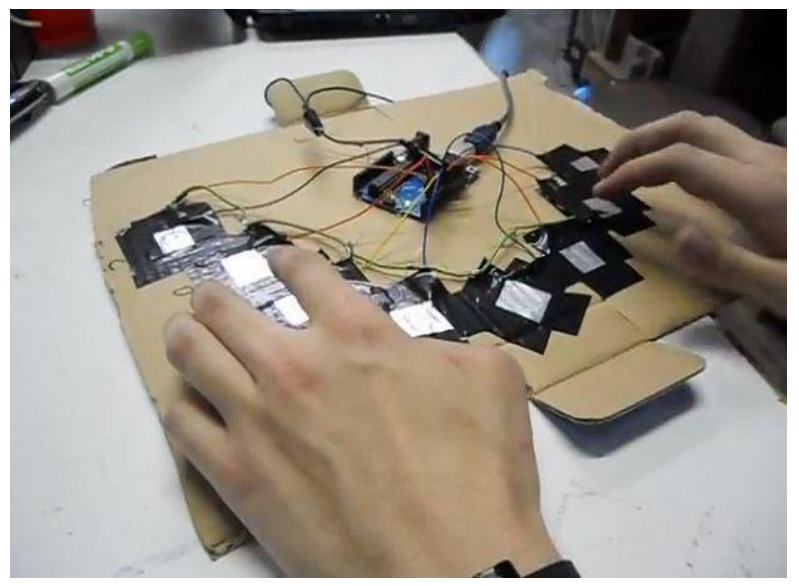

Figure 7. Example for capacitive touch [7]

As from Figure 5, when the keys are pressed, the output is dependent on the key pressed out of 6 (Braille Cell Format), (Figure 8).

Braille cell is a $3 \times 2$ matrix and has its own size standards. Now these braille cells are 6 raised dots that arranged in 2 parallel rows. The blind people sense these dots as they place their finger on it.

The braille is designed such that each cell represents a character/alphabet and there are 64 combinations as such to represent the alphabets, numbers and many more.

Now the circuit design for the typing area is based on the Perkins Braille Format. Perkins braille keyboard is type of a typewriter when each key is corresponding to the six dots of the braille cell, as seen in the Figure 9. There are 2 extra keys for backspace and line spacing. These devices were used to take down notes or to print note books for the visually impaired people. (Figure 1)

Small border can be given on the surface of the typing area so that the users sense the presence of the keyboards circuit and differentiate between the 6 keys easily.

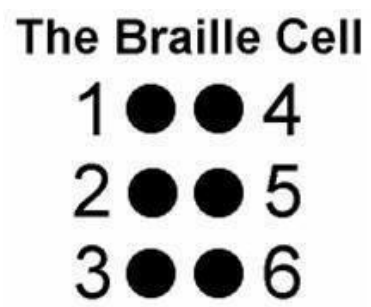

Figure 8. Braille CELL [8]

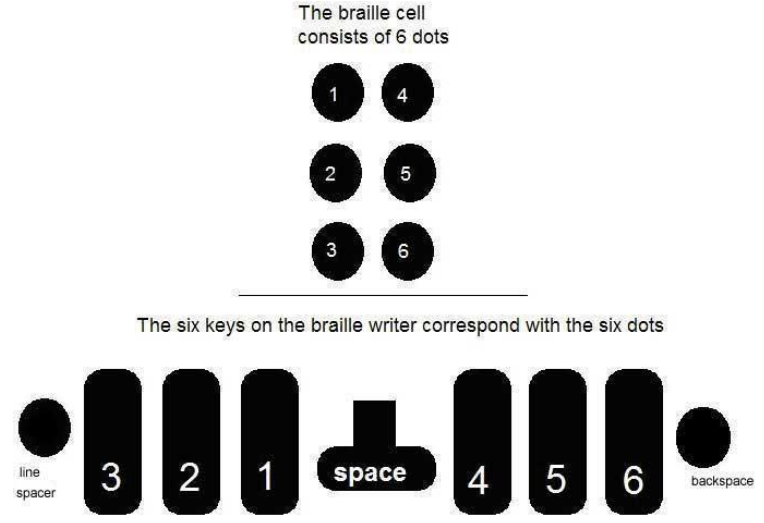

Figure 9. Perkins Braille Based Keyboard format [9]

Navigation keys: (Cursor Pad, Home and Menu)

As visually impaired people have difficulty with using the Smart phone and browsing through the phone is a big problem, so these navigation keys would be helpful to browse through different apps.

As seen in Figure 10, these Buttons are attached to the Keyboard such that the person can interact with Smart Phone or PC.

These navigation keys are button that will be placed on the front plate of the pocket braille. These buttons connected to the Arduino and when they are pressed they will be responding accordingly. As the pocket braille would be connected to the phone with Bluetooth, when the keys are pressed according to that the action would occur. There is a cursor pad, a home and a menu button present.

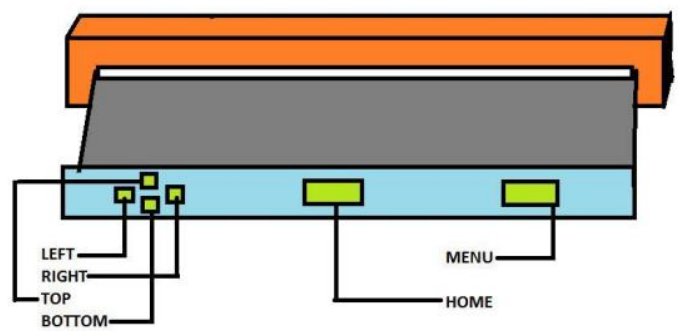

Figure 10. Navigation keys

Home button would move the screen of the phone to the home screen of the phone and the menu button would be acting as options present in the mobile phone so that further resources can be chosen. The cursor button will be responsible for helping the visually impaired people to browse the smart phone and change between the apps. With the cursor button, they can move left and right and open different apps.

For Reading: 
There will be Perkins Braille Format DOTS/Cells that will present on top of keyboard. Now these braille cells will be designed by using MEMS Technology (Mini Actuator working on tiny voltage). The word format will be controlled by the Micro controller. There will be 7 Braille Cells to read 2 or 3 words in a stretch.

Small Micro Actuators would be used that would have a linear motion on them and when they are kept vertical, these could be used as the braille dots that would be help the visually impaired people to sense that dot.

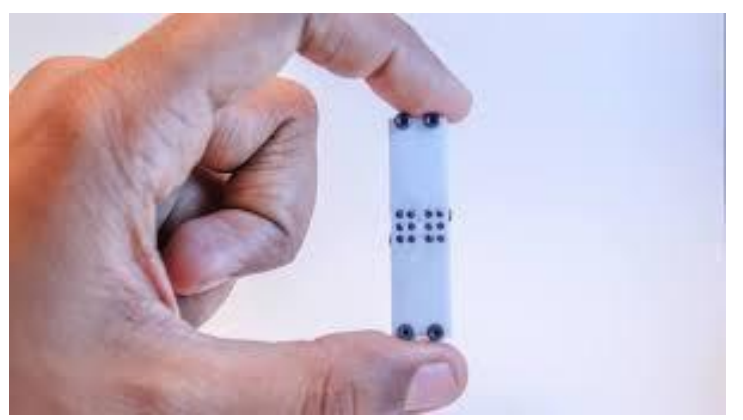

Figure 11. Refreshable Braille pins [10]

Micro-Electro-Mechanical Systems, or MEMS, is a technology that in its most general form can be defined as miniaturized mechanical and electro-mechanical elements (i.e., contrivances and structures) that are made utilizing the techniques of microfabrication. The critical physical dimensions of MEMS contrivances can vary from well below one micron on the lower cessation of the dimensional spectrum, all the way to several Millimeter. Likewise, the types of MEMS contrivances can vary from relatively simple structures having no moving elements, to profoundly intricate electromechanical systems with multiple moving elements under the control of integrated microelectronics. The one main criterion of MEMS is that there are at least some elements having some scarcely mechanical functionality whether or not these elements can move. The term used to define MEMS varies in different components of the world. In the Amalgamated state they are predominantly called MEMS, while in some other components of the world they are called "Microsystems Technology" or "micro machined devices". [11].

While the functional elements of MEMS are miniaturized structures, sensors, actuators, and microelectronics, the most eminent (and perhaps most intriguing) elements are the micro sensors and micro actuators. Micro sensors and micro actuators are congruously categorized as "transducers", which are defined as contrivances that convert energy from one form to another. In the case of micro sensors, the contrivance typically converts a quantified mechanical signal into an electrical signal. [11]
These miniaturized actuators would be placed on the pocket braille, the size of this would be such that 6 to 7 braille cells can be placed. (As seen from Figure 13)

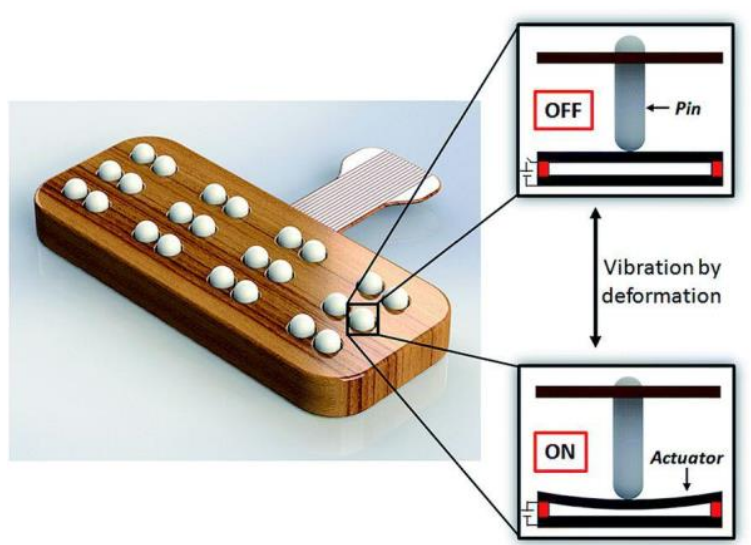

Figure 12. Actuator based Braille Pins [12]

\section{Communication}

By using the braille back service in SMART phones/PC, this device can be connected via Bluetooth, USB and aux (Sound Communication).

Braille Back service is an appropriable service that helps the visually impaired in using the braille devices. The Talk back service of android is linked to this service that gives a speech experience also. This service helps the user to navigate through the phone and interact with the device using the Navigation keys present on the Pocket braille. And also with this service the text present on the screen can be put on the MEM's Display, acting as braille display.

As visually impaired can't operate Smart devices, a question arises of how the users would connect the phone to the pocket braille. This problem could be solved by the use of Bluetooth auto connect, it is an application present in google play store. This app automatically connects the phone to the pocket braille prior that at least once the connection has to be established.

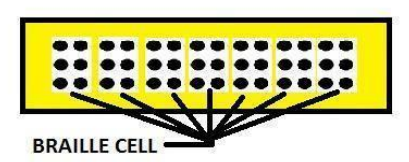

Figure 13. Braille Cell Layout 


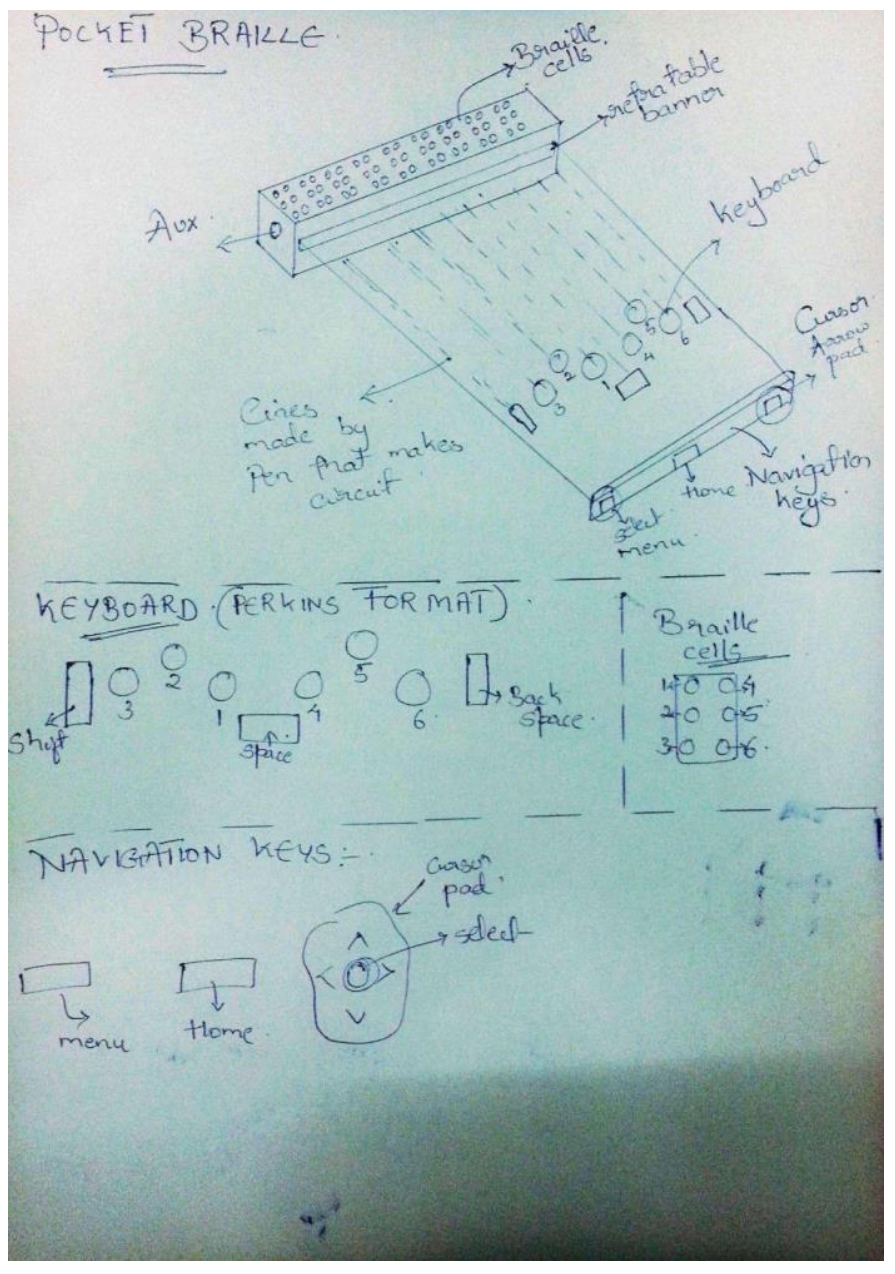

Figure 14. Project Layout

\section{Results}

This project is planned to serve the citizenry that cannot see, interpret or write as normal human beings. There are many equipment's which help the visually impaired lead a normal life.

The main objective of this project is to create a consumer device which enables a visually impaired to interpret messages and calls from their cell phones to an external device through Braille code. In order to remove the difficulties being faced by a visually impaired, this project is being implemented. This Consumer device will be assisting the visually impaired, it will act as a Mobility tool.

This device is used to interact with their mobile phone and also helps the visually impaired to perform Note-taking tasks but without the use of any special keyboard.

\section{Benefits to Oman}

Braille, used as the communication tool for blind individuals has been linked to an important point 'literary argument'. This has allowed its users to gain an understanding of literacy of people who are not visually impaired.

Though with the recent increase in the use of technology, our project will incorporate this technology into making Braille more understandable and portable to the visually impaired. This has been achieved in the form of Braille keyboard readers and Braille reader.

-The project which includes the Braille reader has got pins which rise and fall in accordance to the Braille dots. This portable device is either attached to the computer or to the handheld devices such as mobile phones. It also includes the Braille keyboard which allows the users to write into whichever devices it's connected to.

-Since hard-copy Braille is more bulky and takes more place to store an electronic device is preferred more. The portable Braille keyboard which is already in use in terms of weight is heavier and it is expensive to prepare.

-The Braille keyboard reader is lightweight and less expensive clearing out the two problems faced in the already existing one thus making it more accessible to its users.

\section{Conclusion}

This project has many advantages in many aspects of the field.

Academic, scientific / innovative significance:-

-The improvements in Braille technology can be used to assist students with visual impairment. Assistive Technology (AT) is a kind of technology which can be used to enhance the basic skills of a visually impaired student. This technology provides them with appropriate tools, devices and technologies to meet their learning needs and use AT for research, note taking and for other academic uses.

-AT is a fundamental work tool which is equivalent to the pencil and paper for the non-visually impaired students. Though it shouldn't give them an unfair advantage it should give them enough independence to effectively compete with their non-visually impaired fellow students.

-This technology helps the visually impaired to access and store information received at school, home and the community.

Potential economic impacts of the project:-

-During a study, it was found that people who had learnt Braille had a higher employment rate compared to people who did not learn.

-This made them more self-sufficient as they had spent more time learning that than those who did for print. These people were employed at places which work for the betterment of the visually impaired. Since they have the knowledge of Braille, their employment was significantly higher rate.

Expected social/ Cultural/ Educational/ benefits:-

-With the introduction of braille the possibility of achieving written culture for the blind became possible. It allowed for a fluency which was not possible before since it was mostly restricted to oral communication.

-Braille language gives an independence to its users. This has helped them a lot because during the Industrial revolution the visually impaired were often devalued for their inability to take part in the common roles.

-The use of this language has made then achieve a better connectivity in the community. They can independently read or write or understand information in a community which used only oral communication. 


\section{ACKNOWLEDGMENT}

We owe the completion of our project to God Almighty and our professors who helped and supported us during the making of the project. Our deepest thanks to our Professor, Mr. Akhilesh Kumar Roy, our Head Of Department for advising us and supporting us always. We express our thanks to Mrs. Anasuya Patil for extending her guidance and support. We would also thank our Institution and our faculty members without whom this Project would have been a distant reality. We also extend our heartfelt thanks to our respective families and well-wishers.We gratefully acknowledge Al Noor Blind association, Al-Khuwair branch, for giving us their time to help us understand the lifestyle of a visually impaired person, and also helping us understand the problems they face.

We also would specifically like to thank Mr. Mohammed AlHarthi, member of Al Noor Blind association, who helped us understand how the braille letters are read and written.

\section{References}

[1] Braille Note takers. (n.d.). Retrieved from Boundless Assitive TECH: http://www.boundlessat.com/Blindness/Notetakers

[2] Circuit scribe pen. (n.d.). Retrieved from Circuit scribe : https://www.circuitscribe.com/product/circuit-scribe-pen-single/
[3] TRT
Banners. (n.d.)
Retrieved
from

https://www.trtbanners.com/retractable-banner-pen-1-000

[4] Arduino. (n.d.). Retrieved from Arduino Micro: https://www.arduino.cc/en/Main/arduinoBoardMicro

[5] Capacitive sensing. (n.d.). Retrieved from Arduino: http://playground.arduino.cc/Main/CapacitiveSensor?from=Main.CapSe nse

[6] Capacitive Sensing. (n.d.). Retrieved from Arduino: http://playground.arduino.cc/uploads/Main/CapSense.gif

[7] Capacitive touch Arduino keyboard piano. (n.d.). Retrieved from Instructables: http://www.instructables.com/id/Capacitive-TouchArduino-Keyboard-P iano/

[8] History Braille. (n.d.). Retrieved from Braille works: https://brailleworks.com/wp-content/uploads/2013/11/Braille-Cell.jpg

[9] Perkins Brailler. (n.d.). Retrieved from Faculty UMB: http://www.faculty.umb.edu/wendy_buckley/BrailleI/class01/lessono ne. html.

[10] Refreshable Braille Display and braille Keyboard. (n.d.). Retrieved from Hackaday: http://hackaday.com/2016/04/28/refreshable-braille-displayand-braille].keyboard.

[11] What is MEMS. (n.d.). Retrieved from MEMS Exchange: https://www.mems-exchange.org/MEMS/what-is.html

[12] Vibro Tactile Actuator. (n.d.). Retrieved from Publishing RSC: http://pubs.rsc.org/-

/content/articlelanding/2015/ra/c5ra03043a\#!divAbsttract 